\title{
FUTURE OF CITIES: URBAN SPACE AND LIFE IN THE AGE OF PLATFORMS
}

\section{LOVRO KONCAR-GAMULIN}

Technical University of Vienna, Faculty of Architecture and Spatial Planning, Karlsplatz 13, 1040 Vienna, Austria

Tutors: Univ.Prof. Dipl.-Ing. Mag.phil. Dr.phil. Peter Mörtenböck; Senior Scientist, Arch. Dipl.-Ing. Dr.techn. Helge Mooshammer

Theme of the dissertation: Platform urbanism

lovro.koncar-gamulin@tuwien.ac.at

\begin{abstract}
Digital platforms have already expanded their reach over a broad range of urban services and cemented themselves at the core of urban life by capitalising on their vast troves of data, all of which has allowed them to enter partnerships with city administrations and thereby claim ownership of more and more urban space. Considering the increasing entwine-ment of the digital realm with physical space, facilitated by platform urbanism, the Internet of Things and advance-ments in immersive technologies, this paper recognises and discusses the importance of key democratic features requi-red to tackle urban challenges in a context-specific way, and to protect urban space from platform monopolies - open data utilisation and user participation. The purpose of this paper is to provide new views on the detrimental nature of digital platforms' urban interventions, as well as to address these issues in the context of the new, spatial or augmented era of the internet - Web 3.0.
\end{abstract}

KEY WORDS: platform urbanism, augmented space, data, participation

\section{Introduction}

Digital platforms responsible for the shift of many aspects of urban life to the digital realm, such as the way we work, communicate, shop and learn, increasingly present themselves as optimal structures capable of meeting a wide range of challenges in the urban realm. Platform technologies and data-driven urbanisation are becoming more and more 
central to urban politics - urban space is a vast source of data which digital platforms can extract and process, and they can then create and offer services to that very urban space based on that very data (Mörtenböck \& Mooshammer, 2021). Digital ecosystems such as Google, Amazon, Facebook and Uber have promised us improved access, unprecedented participation and remarkable convenience which has allowed them to penetrate into a broad range of services including healthcare, education, public transport, housing, and even city planning, earning them the role of quasi-public urban actors.

This paper zooms in on their democratic promises and discusses the increasing entwinement of the digital realm with physical urban space, facilitated by the above-mentioned phenomenon known as platform urbanism(1). The increased presence of digital platforms in urban space, assisted by rapid advancements in immersive technologies such as aug-mented reality, calls for analyses of their urban interventions as well as commitments to democratic data-utilisation and user participation features that always eventually manifest in urban space. As for the space itself, the nature of aug-mented urban space(2) the platforms are aiming for is further examined.

\section{Data Utilisation and User Participation in the Age of Platforms}

To understand the nature of urban transformation led by digital platforms, it is important to note that it occurs simulta-neously in the physical and the digital realm, and perhaps the best way to perceive the connection between the two is by discussing data. The collecting and processing of an enormous amount of data both online and from urban space is one of the fundamental features of digital platforms, and the fact that there are more and more ways to capitalise on that data makes it easier for them to seek partnerships with cities (Mörtenböck \& Mooshammer, 2021; Lee et al, 2020). For instance, Airbnb and Uber have entered into partnerships with city administrations to capitalise on their vast troves of data, Airnb through their platform Airbnb City Portal and Uber through their platform Uber Movement, which exchang-es valuable traffic data with local governments for short-term or long-term gains. This phenomenon exposes similarities between platform urbanism and the preceding smart city narrative. Within the smart city discourse, public-private part-nerships capitalising on mass data accumulation with corporate interests that control urban platforms received strong criticism (Smith \& Martin, 2020 as cited in Greenfield, 2013; Thrift, 2014; Vanolo, 2016; Marvin \& Luque-Ayala, 2017).

Still, data is presented to us by digital platforms as a simple tool, capable of calculating the solution to almost every urban challenge, from small-scale interventions to city planning. But how can data by itself accurately depict the needs of the city and its residents, especially considering its incapability of understanding local context (Hollis, 2021)? Plat-forms operate globally, but the urban spaces in which they interfere are extremely context-dependant. 
Therefore, the in-evitable side-effect of data-driven urbanisation is the disconnection between the digital and the physical aspects of urban space. For this reason, more emphasis on citizen participation, both online and offline, together with a more accessible data utilisation would greatly contribute to facing upcoming urban challenges in a context-specific way. However, promises of unprecedented participation by digital platforms still resemble initiatives of smart city vendors such as IBM, Cisco and Microsoft and their completely data-focused views of user participation. Considering that the smart city idea of governance consisted of managing chaotic urban processes with analytics and big data (Marvin \& Luque-Ayala, 2017), actual participation simply consisted of smart citizens being enrolled into various databases and their data being processed (Smith \& Martin, 2020).

With that in mind, what does it mean to participate in the age of platform urbanism? Digital platforms are increasingly perceived as digital public spaces with users being depicted as co-creators of the future and with access to open-data being presented as a technology-enabled path to democracy. However, in the age of platforms and social media, but also of sensors, movement trackers etc, everyday life is considered as participation. Platforms and tech companies use the idea of participation simply to legitimise their urban interventions. Additionally, the authoritarian structure of these technocapitalist corporations such as Alphabet (Google) and Facebook, where a handful of executives and major share-holders make all the decisions, also raises questions of the plausibility of their democratic promises, and consequently raises concerns about the ambitions behind their urban interventions. How can citizens contribute to tackling urban challenges with their ideas and through deliberation instead of just with their data, especially those without access to platform services? The answer might lie in collectivising data (Sadowski, 2020), but in a way that helps citizens inte-grate digital platforms to their existent ways of participation, as well as in providing new ways of both online and of-fline cooperation.

\section{Platform Urbanism in Augmented Space}

The ambitions of digital platforms have always included claiming as much urban space as possible. Google plans data-oriented smart districts in cities around the globe and Apple increasingly produces not just new stores but branded town squares. However, the prospect of adding a digital layer onto almost anything opened endless possibilities for plat-forms' further involvement in urban space and marked the beginning of the internet's new era - Web 3.0, or simply, spatial web. Physical space is limited, but it can accommodate an infinite number of digital layers pinned to the same location. Thus, the entire urban space will be available to digital platforms for any intervention they see fit, which pos-es a fundamental threat to urban space and culture (Nelson, 2018).

In the same augmented space, people will begin to have dramatically different ex- 
periences depending on which digital layers they choose to engage with. This opens new questions of ownership, such as, who owns the space - those who own the physical land, or the company who owns the digital layers above it? Even though parks, squares, roads etc are void of corporate control, platforms as both providers of infrastructure and content moderators could easily monopolise augmented space and take control over its digital aspect (Koncar-Gamulin, 2021). It is no secret that crowdfunding plat-forms have already made it possible for private interests to intervene in public space, so groups with more money can claim more space and thereby steer urban development in the direction they see fit (Mörtenböck \& Mooshammer, 2021).

Additionally, augmenting space with the IoT(3) might exacerbate already well-known issues with the web today such as confirmation bias(4) and feedback loops(5). Therefore, bringing issues such as the importance of citizen participation in platform processes, open data, and the engagement of local administrations to public discussion is critical for our cities' future as more and more aspects of the IoT and digital platforms start appearing in material form.

\section{Conclusion}

This paper focuses on the nature of urban transformation caused by platform urbanism by examining parameters such as data-accumulation and utilisation, and the user participation that has allowed platforms to cement themselves at the core of urban life, followed by analysis of augmented space that platforms aim to next claim ownership of. The research suggests that there is too much of an emphasis on data-accumulation simply because it can be monetised and promotes platforms' corporate interests; however, user participation is needed for context-specific ways of urban interventions.

To successfully tackle urban challenges and strive for democratic urban space, data must be collectivised, and access to platform services should be provided for diverse ways of online and offline participation. This is especially relevant considering the increased entwinement of digital platforms with urban space through immersive technologies and Web 3.0, as the internet begins to materialise in space. The research opens new questions of the ownership and control digi-tal platforms can easily claim over augmented space, thus coming to dominate urban life.

\section{Footnotes}

[1] See Sarah Barns (2020). Platform Urbanism: Negotiating Platform Ecosystems in Connected Cities.

[2] See Thomas Chan (2021). Rethinking space + place: negotiating a social realm 
between mobile technology and architecture.

[3] Internet of Things

[4] Everything online agrees with our beliefs.

[5] We see more of the stuff we like.

\section{Literature}

Hollis, L. (2021) A-Z of Platform Urbanism: S. Schmoozing. Platform Austria. https:// www.platform-austria.org/en/blog/a-z-of-platform-urbanism-schmoozing

Končar-Gamulin, L. (2021). Apple, Facebook, Google, Uber ili kad pohlepa zavlada. Express. https://express.24sata.hr/top-news/apple-facebook-google-uber-ili-kadpohlepa-zavlada-25082

Lee, A., Mackenzie, A., J. D. Smith, G. \& Box, P. (2020). Mapping Platform Urbanism: Charting the Nuance of the Platform Pivot. Urban Planning, 5(1), 116-128. https://doi.org/10.17645/up.v5i1.2545

Marvin, S., \& Luque-Ayala, A. (2017). Urban Operating Systems: Diagramming the City. International Journal of Urban and Regional Research, 41(1), 84-103. https:// doi.org/10.1111/1468-2427.12479

Moertenboeck, P. \& Mooshammer, H. (2021). Platform Urbanism and Its Discontents. nai010 publishers. 30-35.

Nelson, J. (2018). When Digital Layers Reshape Physical Social Spaces \& Change Culture. Medium. https://jndesign.medium.com/when-digital-layers-reshapes-physical-social-spaces-change-culture-3f3f315b87f

Sadowski, J. (2020). Too Smart: How Digital Capitalism is Extracting Data, Controlling Our Lives, and Taking Over the World. The MIT Press. 192-194.

Smith, A. \& Martin, P. P. (2020). Going Beyond the Smart City? Implementing Technopolitical Platforms for Urban Democracy in Madrid and Barcelona. Journal of Urban Technology, 311. doi:10.1080/10630732.2020.1786337

\section{Bibliography}

Barns, S. (2020). Platform Urbanism: Negotiating Platform Ecosystems in Connected Cities. Palgrave Macmillan. 18-20.

Chan, T. (2021). Rethinking space + place: negotiating a social realm between mobile technology and architecture. Ryerson University. https://doi.org/10.32920/ryerson.14657889

Greenfield, A. \& Kim, N. (2013). Against the smart city (The city is here for you to use Book 1). Do projects.

Thrift, N. (2014). The 'sentient' city and what it may portend. Big Data \& Society, 1(1), 1-19. https://doi.org/10.1177/2053951714532241

Vanolo, A. (2016). Is there anybody out there? The place and role of citizens in tomorrow's smart cities. Futures, 82, 26-36. https://doi.org/10.1016/j.futures.2016.05.010 